\title{
Anxiety of Students in Visualization, Analysis, and Informal Deduction Levels to Solve Geometry Problems
}

\author{
Sunardi, Erfan Yudianto, Susanto, Dian Kurniati, Rahmad Dwi Cahyo \\ University of Jember \\ Jember, East Java, Indonesia
}

\section{Subanji}

State University of Malang

Malang, East Java, Indonesia

\begin{abstract}
This research aims to describe the anxiety of grade 9 students to solve geometry problems based on the IDEAL stages, that is, identify, define, explore, act, and look back. The subjects were three students who each had one student at each level, namely, visualization, analysis, and informal deduction. The data were collected through tests and interviews. To guarantee the validity and reliability of the research, the triangulation technique was used. The findings and conclusions were as follows: students' visualization anxiety could be observed in the explore stage, which was caused by their confusion to use the Pythagorean theorem in which only one side was known, and in the act stage, which was caused by the thinking barrier as they were unable to write the solution and add the explanation; students' analysis anxiety could be observed in the act stage, which was caused by their confusion to ponder over the working time and the use of a wrong method, and in the look-back stage, which was caused by their uncertainty and worry for giving incorrect answers; and students' informal deduction anxiety appeared in the act stage, which was caused by the thinking barrier as they were unable to describe the use of proportion of base and perpendicular of a right triangle.
\end{abstract}

Keywords: Anxiety; IDEAL Stages; Geometry; Van Hiele.

\section{Introduction}

Anxiety about one subject in the teaching and learning process could occur because in the earlier education stage, students had not yet understood the material well (Foose, 2014; Saglam, Türker, \& Umay, 2011). The study conducted by Putwain (2007) showed that a low anxiety level helped children to learn more optimally, while a high anxiety level ruined the concentration of students in 
performing their learning activities. Even if a student wanted to organize the information that was provided, that information was just spinning around in his/her brain and was not processed or stored in his/her long-term memory (Rix, 2015).

Khotimah (2013) stated that the percentage of senior high school students in Yogyakarta who were able to measure the distance and angle between two objects (points, lines, and areas) in the space during the mathematic national exams was $57.52 \%$. Yudianto and Sunardi (2015) stated that based on the daily test results of grade 10 students in SMA Darussholah Jember on the subject of three dimensions, 61 out of 82 obtained a score of $<60$, while the remaining 21 obtained a score of $\geq 60$. This low exam result was one of the indicators that students had problems in completing geometry questions. Ideally, students should easily understand geometry because geometric ideas, such as lines, dots, and field, had been already known even before they start going to school, but in reality, geometric material is still not mastered by students.

The aim of helping students apply geometry in daily life is to identify the difficulties they face. One of these difficulties is the anxiety students feel when faced with geometry problems. Anxiety can be observed at each stage of solving geometry problems. Each student experiences various anxieties when completing the problem of tremor. Not everyone who solves geometry problems has the same geometric ideas. According to van Hiele's theory, students go through five levels to learn geometry. These levels explain how we think and what kind of geometric ideas we think, not how much knowledge we have. Therefore, every student on each van Hiele level has a different anxiety tendency. To identify the location of the anxiety that arises, it is necessary to choose a problem-solving approach that can determine the geometry problemsolving process in detail. The IDEAL model, rather than the Polya model, is more appropriate to use because it is more detailed than Polya, that is, it understands the stage of the problem, identifies the stage, and defines it.

According to van Hiele, there are five levels of geometrical thinking, namely, visualization, analysis, informal deduction, deduction, and accuracy/rigor. In this study, three levels were selected, namely, visualization, analysis, and informal deduction, because the deduction and rigor levels were only found in university students. Junior and senior high school students have not been able to think deductively in learning geometry.

Based on the explanation above, the purpose of this study was to describe grade 9 students' anxiety on visualization, analysis, and informal deduction levels in solving geometry problems through the IDEAL stages: identify, define, explore, act, and look back.

\section{Literature Review}

Anxiety can be recognized by indicators that exist in the physiological and behavioral symptoms of someone (Chang, Sprute, Maloney, Beilock, \& Berman, 2017). Physiological symptoms can be observed in the cardiovascular system (heart palpitations and fainting curiosity), breathing (shortness of breath, 
pressure on the chest, and a sense of strangulation), neuromuscular system (insomnia, pacing, and taut face), gastrointestinal system (loss of appetite, nausea, and diarrhea), urinary tract (cannot hold pee), and skin (facial blushing, sweating, and feeling chills on the skin). Behavioral symptoms are divided into two categories: cognitive and affective behavior. Examples of cognitive behavior are disturbed attention, bad concentration, forgetful, wrong judgment, thinking barriers, loss of objectivity, confusion, fear, and nightmares. Examples of affective behavior are anxiety, impatience, easily distracted, suspense, horror, nervousness, apprehension, guilt, and shame (Stuart, 2006).

According to Stuart (2006), anxiety level is divided into four categories, namely, mild anxiety, moderate anxiety, severe anxiety and panic. Trujillo and Hadfield (Peker, 2009) stated that the cause of math anxiety could be classified into three: personality (psychological or emotional), social or environmental, and intellectual factors. The emergence of anxiety has no definite cause, although researchers have stated that some of the factors previously mentioned are its causes (Rector, Bordeau, Kitchen, \& Massiah, 2005). Anxiety could be considered different for everyone, so each individual experiences a different type of anxious feelings from others (Marsh, 2018; Ramirez, Chang, Maloney, Levine, \& Beilock, 2016; Wu, Willcutt, Escovar, \& Menon, 2014).

Not all people think about geometry in the same manner. According to the theory of van Hiele, students must pass through five stages in learning geometry. These levels describe how we think and the type of geometric ideas we think, rather than how much knowledge we have. The significant difference between levels involves our capability to think geometrically (Walle, 1994).

Van Hiele's five geometric thinking levels are as follows (Armah, Cofie, \& Okpoti, 2018; Fitriyani \& Widodo, 2018; Walle, Folk, Karp, \& Williams, 2013; Yudianto et al., 2018):

Level 0: Visualization. Students know and name shapes based on the area characteristics and appearance of those shapes will form an embodiment approach.

Level 1: Analysis. Students can explain all shapes in a group other than the form unit. At this level, students begin to understand that a collection of shapes are classified based on the similar features/characteristics.

Level 2: Informal deduction. The objects of thought are the features of the shape. With a deeper understanding of dealing with the thought of "if-then," the shapes can be classified only by using minimal characterization.

Level 3: Deduction. The type of thought that characterizes a thinker on level 3 is making a list of axioms and definitions to make the theorem. They also prove the theorem by using an articulated logical thinking. 
Level 4: Accuracy/Rigor. The objects of attention are essentially their own base systems, not only the conclusion in the system. There is an appreciation of difference and relationship among the various base systems.

Every student who is on the fifth level of the van Hiele levels can experience anxiety when solving geometry problems. When it happens, the five levels have different characteristics. To identify the difference, the IDEAL model was selected in this study rather than the Polya model because it is more detailed than Polya. The IDEAL problem-solving approach was introduced by Bransford and Stein (1993) to improve thinking ability and skill in problem-solving. The word IDEAL does not intend to show that it is the perfect or the best method, but each letter of the word IDEAL is an important component in the problemsolving stage.

I-Identify the problem. This stage is the initial phase in solving the problem. In this stage, students identify the issues.

D-Define and represent the problem. In this stage, students should be able to sort out all the information that has been known and analyze it to determine the purpose of the given issue.

E-Explore possible strategies. The next step after determining the purpose of the question was finding and selecting suitable strategies which can be used to find the purpose that had already been specified in the previous step.

A-Act on the strategies. This stage is a continuation of the previous stage that is carrying out the strategy that has been selected so that the answer to the question can be found.

L-Look back and evaluate the effects of your activities. This stage needs to be completed to recorrect what students have done.

\section{Research Method}

This research was qualitative in nature and employed an exploratory descriptive method (Ridder, Miles, Huberman, \& Saldaña, 2014). It was projected to describe the anxiety of grade 9 students on visualization, analysis, and informal deduction levels in solving geometry problems based on the IDEAL stages. The design was operationalized because qualitative descriptive research constituted a design that was aimed at describing, combining, analyzing, and interpreting the situation of an individual, institution, or group (Kurniati, Purwanto, As'ari, \& Dwiyana, 2018). This research was conducted at the junior high schools 1, 2, 3, and 6 of Jember, carrying on odd semester 2018/2019 academic year. One class was selected from the grade 9 of each school as the subjects. The selection of the subject for visualization, analysis, and informal deduction levels was based on the highest number of correct answers on van Hiele geometry tests. If the number of correct answers was equal, the selection would be determined from the answers of the geometry test and the score of the anxiety questionnaire. In the process of solving the geometry test, students who were able to provide the correct solution were selected, then the moderate category was selected from the geometry anxiety's score. The last step was selecting the results of interviews on the subjects who still had similarities on the total correct answers of the van Hiele test, geometry test, and anxiety score. If there were students who had 
similarities, then they were selected to explain the anxiety condition based on the category of moderate anxiety. The problem in this study is presented in Figure 1.

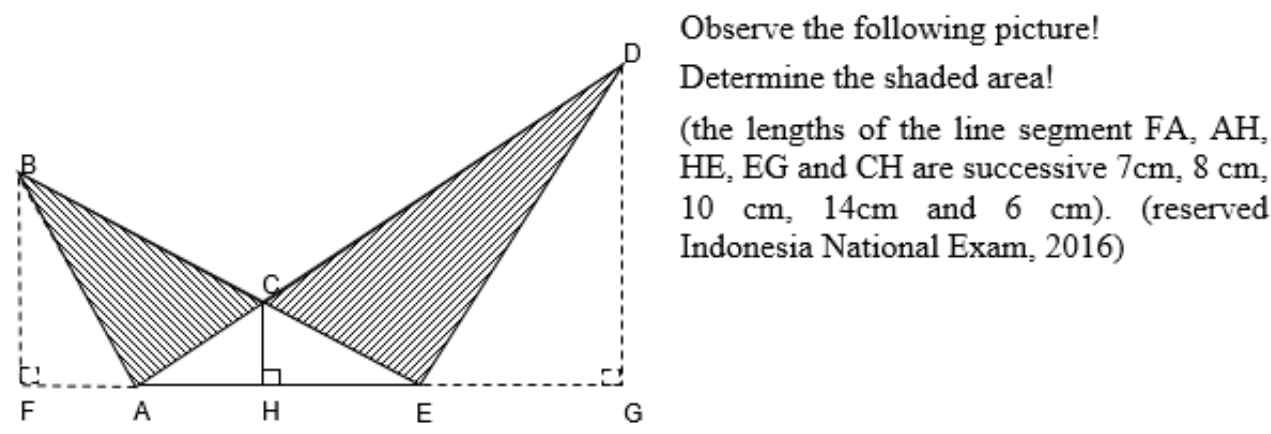

Figure 1. Geometry test problem

\section{Results}

The initial step to obtain the data in this study was begun by administering the van Hiele geometry test to the subjects. The number of students who took the van Hiele geometry test were 138: 36 students were from junior high school 1, 32 from junior high school 2, 34 from junior high school 3, and 36 from junior high school 6. The results of the classification of van Hiele for visualization, analysis, and informal deduction level are presented below.

Table 1. Results of the classification of van Hiele

\begin{tabular}{|c|c|c|c|}
\hline No. & van Hiele Level & Number of Students & Percentage (\%) \\
\hline 1 & 0 (Visualization) & 9 & 16,37 \\
\hline 2 & 1 (Analysis) & 40 & 72,72 \\
\hline 3 & 2 (Informal Deduction) & 6 & 10.91 \\
\hline \multicolumn{2}{|c|}{ Total } & $\mathbf{5 5}$ & 100 \\
\hline
\end{tabular}

From the 138 students who took the van Hiele test, 40 were on the analysis level, which showed the highest percentage of van Hiele classification results. The results of the questionnaire of 54 students are presented in Table 2.

Table 1. Frequency of students' geometry anxiety level

\begin{tabular}{|c|c|c|c|c|}
\hline \multirow{2}{*}{ van Hiele Level } & \multicolumn{3}{|c|}{ Geometry Anxiety Level } & Number of \\
& Mild & Moderate & Severe & \\
\hline 0 (visualization) & 0 & 9 & 0 & 9 \\
\hline 1 (analysis) & 3 & 30 & 6 & 39 \\
\hline 2 (informal deduction) & 0 & 3 & 3 & 6 \\
\hline Total & 3 & 42 & 9 & 54 \\
\hline
\end{tabular}


To describe the visualization anxiety of Student 1 that was seen through the IDEAL (identify, define, explore, act, and look back) stages in the process of completing the geometry question test, Figure 2 is presented.



Figure 2. Visualization anxiety of Student 1

The figure above shows that in the "act on strategies" stage, Student 1 exhibited symptoms of anxiety because he experienced difficulties in exploring the possible strategies stage and became confused when he started that stage. Four symptoms of anxiety were experienced by Student 1 , namely, (a) he experienced fear when he did not find the solution to the problem, (b) he felt stunted thinking that his friends had already submitted their test, (c) he felt restless when he did not know what to do, and (d) he felt unable to explain anything in this stage. The result of the anxiety symptoms was that defining and solving the problem became stagnant.

To describe the analysis anxiety of Student 2 that was seen through the IDEAL stages in the process of completing the geometry question test, Figure 3 is presented. 


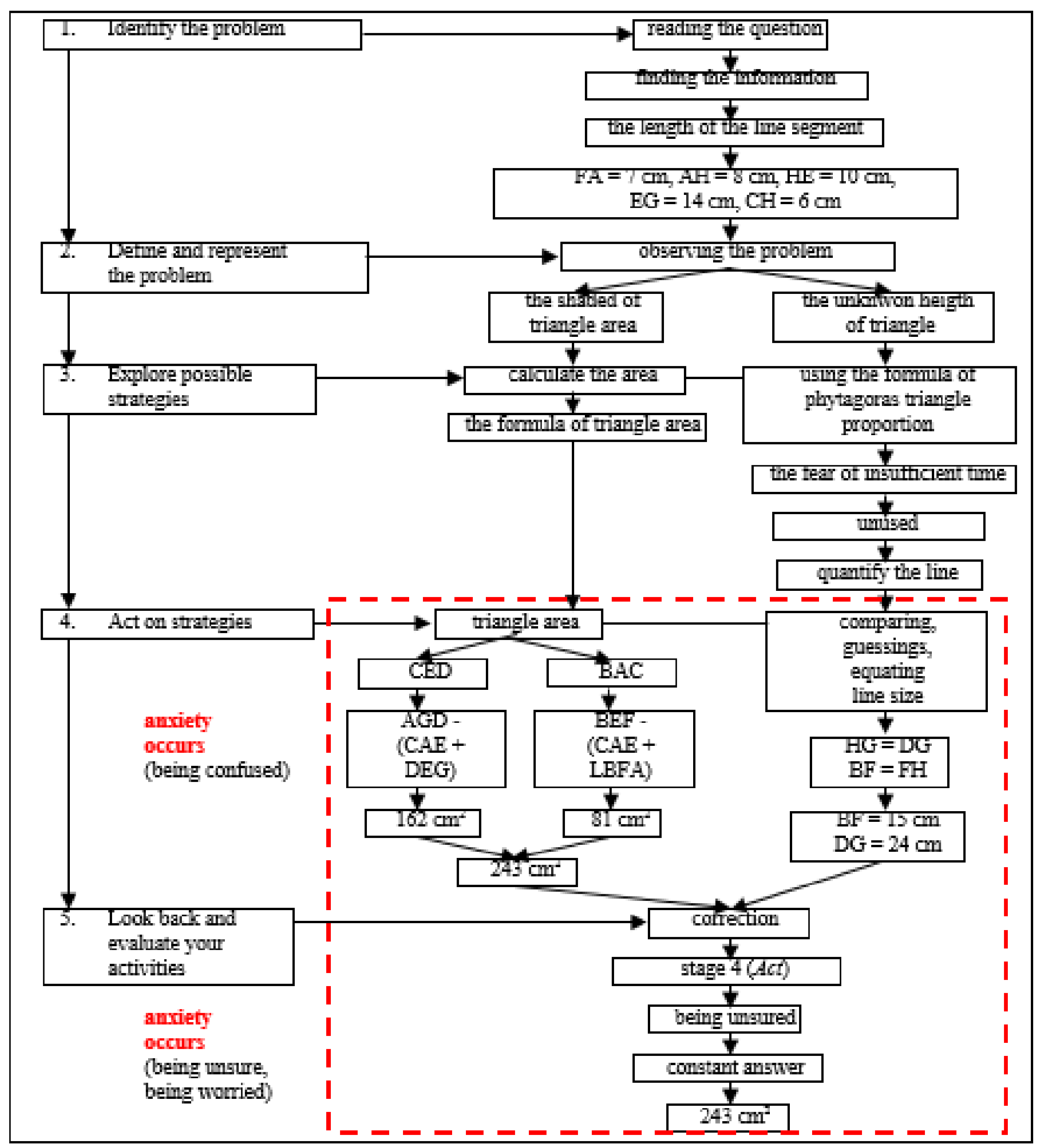

Figure 3. Analysis anxiety of Student 2

The figure above shows that in the "act on strategies" stage, Student 2 experienced symptoms of anxiety. He was confused thinking of the allocation time and using it carelessly. He experienced affective anxiety symptoms on the "look back and evaluate your activities" stage because he gave careless answers and was worried he would fail. He was not sure how to answer the test.

To illustrate the informal deduction anxiety of Student 3 that was seen through the IDEAL stages in the process of completing the geometry question test, Figure 4 is presented. 


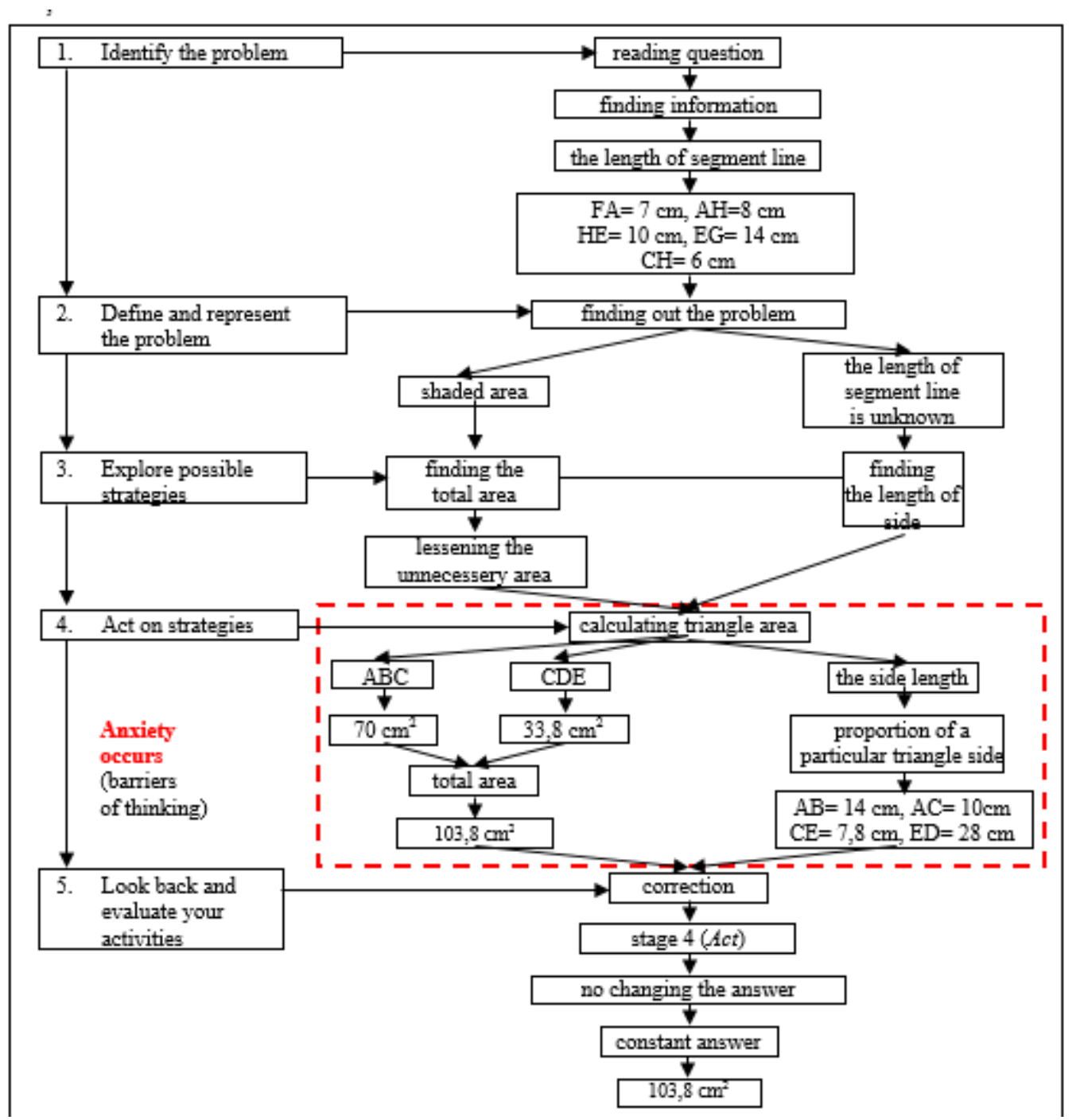

Figure 4. Deduction anxiety of Student 3

The figure above shows that in the "act on strategies" stage, Student 3 exhibited symptoms of anxiety because he experienced thinking barriers and used an incorrect method that resulted in wrong calculations. When he was asked about the answer, he could not explain because he was not sure whether his method was correct.

\section{Discussions}

The anxiety experienced by the students in the visualization level was moderate. This result was proven by some of the anxiety symptoms that they experienced. These students experienced eight anxiety conditions: (a) they felt doubtful when they carelessly answered the geometry test; (b) they felt pressure on the chest when answering the test; (c) they felt tense when they took the geometry test; (d) they became confused when they began answering the geometry test; (e) they were embarrassed or nervous while answering the geometry test, afraid that they did not find the solution to a problem; (f) they felt queasy while answering a difficult geometry test; (g) they felt restless when they did not understand 
what to do to resolve the geometry problem; and (h) they experienced thinking barriers when their friends already submitted their geometry test. The students in the visualization level read the problem and were aware of the length of the line segment in the identify stage. In the define stage, the students understood that the shaded-in area of a triangle and the unknown height of a triangle were being asked. In the explore stage, the students planned to use the Pythagorean theorem but got confused because they were unable to apply the theorem as only one side of the triangle was known and they could not find another solution. In the act stage, the students could not find the solution, got stagnant, provided no calculation and illustration, forgot about triangle congruence, and gave a blank answer. In the look-back stage, the students did not correct their answer and did not find the shaded area of a triangle, and their blank answer remained. The following is an interview excerpt with a student in the visualization level on "explore possible strategies" stage.

PP015 : So what strategy do you use to solve it?

S2015 : It should use [Pythagoras], but it is confusing because there is no height, so suppose there are two sides found in Pythagoras, only the below line segment is found.

The student explained that he will use the Pythagorean theorem to find the unknown side. However, he realized his strategy could not work because he needed two sides of the triangle. The problem was that only one side was known. In the "act" stage, the student could not write and add an explanation to his calculations in question number 2 . Hence, he could not find the solution and could not do anything in that stage. The answer of the students in the visualization level in the "act on strategies" stage is presented in Figure 5.

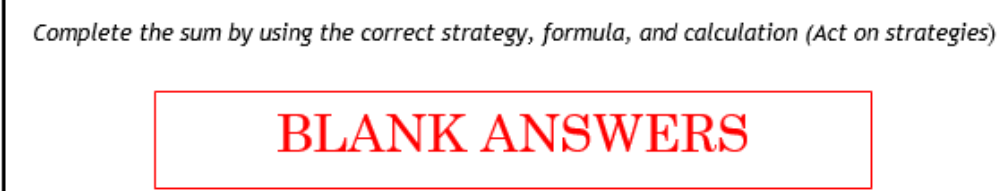

Figure 5. The answer of students in the visualization level in the "act on strategies" stage

The following is an interview excerpt with a student in the visualization level regarding the strategies stage.

PP016 : Oh, okay, so it is stagnant there, isn't it? There is no result.

S2016 : Yes.

Based on the PP015-S2015 and PP016-S2016 excerpts and Figure 5, from the five stages of the IDEAL solution, the emergence of geometry anxiety on students in the visualization level was likely to appear on the "explore possible strategies" and "act on strategies" stages. Based on the anxiety explanation, the students in the visualization level experienced anxiety with a syndrome like "I can' $t$ "; this anxiety was caused by their inability to comprehend the problem and apply mathematical concepts as described by Furner and Berman (Gresham, 2010). 
The anxiety experienced by the students in the analysis level was classified as moderate. Five anxiety conditions became the point of their geometry anxiety, namely, (a) they felt hesitant when the teacher gave unexpected geometry tests that caused heart thumping; (b) they felt unsure when they carelessly answered the geometry test; (c) they were worried about failing the geometry test; (d) they felt hesitant when they did not find the solution to a problem, which made them afraid; and (e) they felt impatient to receive the result of the geometry test. The students in the analysis level read the problem and were aware of the length of the line segment in the identify stage. In the define stage, the students observed the problem involving shaded areas of triangles and the unknown length of triangles. In the explore stage, the students planned to calculate the area of the triangles; measure the line by comparing, guessing, and equating the size of the line; and use the Pythagorean theorem. However, he ended up not using it due to time limitations. In the act stage, the students found the shaded area of triangles from summing up the triangle area of CED and BEC. The last stage is look back. The student was unsure whether his answer was correct or not because he just used a ruler to find the unknown side of the triangles. In fact, he did not change his answers. The answer of the student in the analysis level regarding the strategies stage is presented in Figure 6.

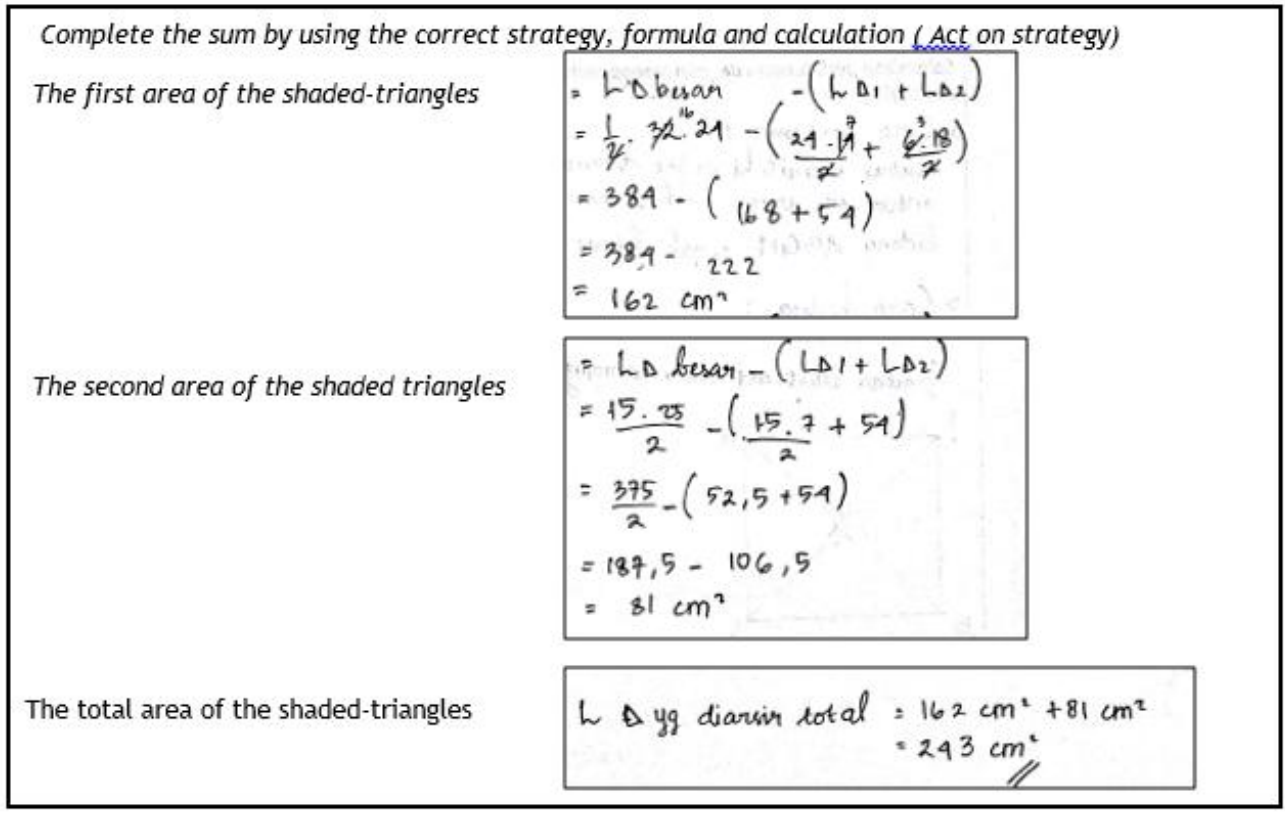

Figure 6. The answer of the student in the analysis level in the "act on strategies" stage

The following is an interview excerpt with a student in the analysis level on the "act on strategies" stage.

PP026 : Great, would you like to show me how to measure to obtain BF as the height of the triangle? You just used this ruler, right?

S3026 : No, it is actually not. I just applied the formula of the square root of one for the square, but there are also cubed, square roots. I am just afraid the time is not enough. 
Based on the interview excerpts and the picture of the answers of the student in the analysis level regarding the act stage, he was able to write down the answers by applying the strategies that he made earlier. Despite his correct answers, the interview revealed that he used the wrong method, because he just presumed to obtain the unknown side from the other side. He measured the length using a ruler and using a proportion to presume the unknown base and perpendicular.

The following is an interview excerpt with a student in the analysis level regarding the look-back stage.

PP031 : Have you already recorrected the steps to get $243 \mathrm{~cm}^{2}$ ?

S3031 : Yes. However, I am not sure about it.

From the five stages of the IDEAL solution, the geometry anxiety of students in the analysis level tended to appear at the "act on strategies" and "look back and evaluate your activities" stages. The explanation of anxiety that was experienced by the students in the analysis level showed similarities with the research of Das and Das (2013), in which they found that the emergence of anxiety influenced students' weakened confidence and motivation in completing geometry problems. As a result, there was a negative mind-set about the completion of math problems using a new method that resulted in students' learning achievement.

The anxiety of the student in the informal deduction level was moderate, which was proven by some anxiety conditions that he admitted experiencing, such as being unsure whether he carelessly provided answers on the geometry test, being forgetful when beginning to answer the geometry test, experiencing confusion when trying to start answering the geometry test, feeling fear when not finding the solution to a problem, and feeling restless when not understanding what to do to resolve the geometry problem. In the identify stage, the student in the informal deduction level read the question and knew the length of the line segment. In the define stage, he knew two problems that involved the shaded-in area and the length of segments of lines $\mathrm{AB}, \mathrm{CE}, \mathrm{ED}$, and AC. In the explore stage, he planned to find the length of the line segment, look for a total area, and reduce the unnecessary area. In the act stage, he calculated the length of the line segment using a proportion of the sides of the triangle, and in the look-back stage, he proofread all stages and was not sure about his answers due to the error in the formula. However, despite this error, he did not change his answers. The following is an interview excerpt with students in the informal deduction level on the "act on strategies" stage.

PP021 : How could it get 14?

S1021 : Because this proportion is 1, another one is 2, and the other one is the cube root.

S1023 : The area of $A B C$ is $10 \times 14$ per 2 .

PP024 : Okay, what about the area of CDE?

$\mathrm{S} 1024:$ hemm ... the result is $70+28 \sqrt{34} \mathrm{~cm}^{2}$.

The answer of the student in the informal deduction level on the "act on strategies" stage is presented in Figure 7. 


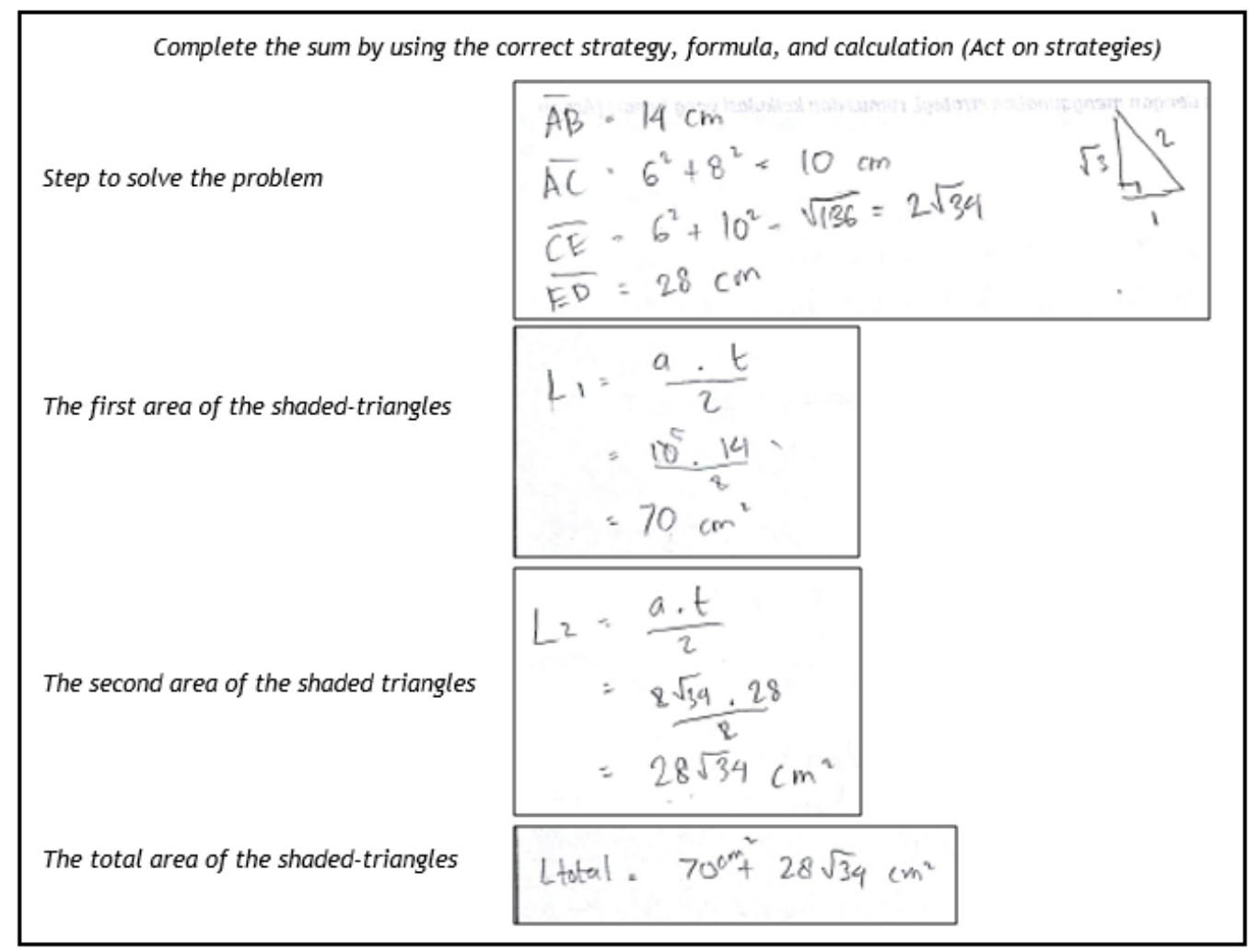

Figure 7. The answer of a student in the informal deduction level in the "act on strategies" stage

Based on the interview excerpt in the act stage and Figure 7, the student in the informal deduction level was able to use strategies, formulas, and calculations in accordance with what he had planned in the "explore the possible strategies" stage. However, when he decided to use a particular triangular side proportion to identify the unknown base and perpendicular, he found errors. He should have used triangle congruence. When he was asked in the interview what was his reason for choosing a particular triangle Pythagoras proportion, he could not explain because he could not ensure that his method was correct. From the five IDEAL stages, the geometry anxiety of students in the informal deduction level tended to appear at the "act on strategies" stage. The explanation of anxiety that was experienced by the students in the informal deduction level indicated similarities with the research of Das and Das (2013), in which they found that the emergence of anxiety influenced students' weakened confidence and motivation in completing geometry problems. As a result, there was a negative mind-set about the completion of math problems using a new method that resulted in students' learning achievement.

\section{Conclusion}

Students in level 0, showed symptoms of geometry anxiety on their physiological conditions, such as they had a tendency to feel pressure on the chest and felt queasy thinking of the solution to a question and not be silent when the problem was distributed; on their cognitive conditions, such as they had a tendency to experience confusion, thinking barriers, and fear; and on their 
affective conditions, such as they had a tendency to feel unsure, experience anxiety, feel dazed, feel impatient, and feel the sensation of strangulation. Out of the five stages of the IDEAL solution, geometry anxiety observed on the students' physiological, cognitive, and affective conditions had the tendency to appear in the "explore possible strategies" and "act on strategies" stages.

Students in level 1, showed symptoms of geometry anxiety on their physiological conditions, such as they had a tendency to feel their heart pounding when they were suddenly given the geometry test, which happened because they had not known or had not prepared the material yet; on their cognitive conditions, such as they had a tendency to feel fear of not finding the resolution to the question, which happened because they were doubtful whether they were able to answer all the questions; and on their affective conditions, such as they had a tendency to feel unsure, worry they would fail, and feel impatient to answer the questions. From the five stages of the IDEAL solution, geometry anxiety observed on the students' physiological, cognitive, and affective conditions had the tendency to appear in the "define and represent the problem," "act on strategies," and "look back and evaluate your activities" stages.

Students in level 2, showed symptoms of geometry anxiety on their physiological conditions, such as they had a tendency to feel like fainting and their facial skin flushed; on their cognitive conditions, such as they had a tendency to experience thinking barriers, fear, and forgetfulness; and on their affective conditions, such as they had a tendency to feel unsure, experience anxiety, and feel the sensation of strangulation. From the five stages of the IDEAL solution, geometry anxiety observed on students' physiological, cognitive, and affective conditions had the tendency to appear in the "act on strategies" stage.

\section{Recommendation}

Students should understand how to cope and control themselves so that geometry anxiety would not negatively affect their performance in solving geometry problems. Other researchers should develop indicators that describe the conditions of anxiety so that wider geometry anxiety conditions could be examined.

\section{References}

Armah, R. B., Cofie, P. O., \& Okpoti, C. A. (2018). Investigating the Effect of van Hiele Phase-based Instruction on Pre-service Teachers' Geometric Thinking. International Journal of Research in Education and Science. https:// doi.org/10.21890/ijres.383201

Bransford, J. D., \& Stein, B. S. (1993). The IDEAL Problem Solver Second Edition (2nd ed.). New York: W. H. Freeman and Company.

Chang, H., Sprute, L., Maloney, E. A., Beilock, S. L., \& Berman, M. G. (2017). Simple arithmetic: Not so simple for highly math anxious individuals. Social Cognitive and Affective Neuroscience, 12(12), 1940-1949. https://doi.org/10.1093/scan/nsx121

Das, R., \& Das, G. C. (2013). Math Anxiety: The Poor Problem Solving Factor in School 
Mathematics. International Journal of Scientific and Research Publications, 3(4), 1-5.

Fitriyani, H., \& Widodo, S. A. (2018). Students ' Geometric Thinking Based on van Hiele' S Theory. 7(1). https://doi.org/10.22460/infinity.v7i1.p53-60

Foose, T. E. (2014). Anxiety. In Encyclopedia of the Neurological Sciences. https://doi.org/10.1016/B978-0-12-385157-4.01080-0

Gresham, G. (2010). A study exploring exceptional education pre-service teachers' mathematics anxiety. IUMPST, 4.

Khotimah, H. (2013). Meningkatkan Hasil Belajar Geometri dengan Teori van Hiele. [Improve results of learning geometry with van Hiele's theory]. Penguatan Peran Matematika dan Pendidikan Matematika untuk Indonesia yang Lebih Baik, 10-16. [Strengthening the Role of Mathematics and Mathematics Education for a Better Indonesia , 10-16]. Yogyakarta: Pendidikan Matematika Fakultas MIPA Universitas Negeri Yogyakarta. [Mathematics Education, Faculty of Mathematics and Natural Sciences, Yogyakarta State University]

Kurniati, D., Purwanto, P., As'ari, A. R., \& Dwiyana, D. (2018). The Truth-Seeking and Open-Mindedness of Pre-Service Mathematics Teachers in the Solution of NonRoutine Problem. International Journal of Instruction, 12(1), 915-930. https://doi.org/10.29333/iji.2019.12159a

Marsh, L. (2018). Understanding Anxiety and Panic Attacks (2nd ed.). London: Mind (National Association for Mental Health.

Peker, M. (2009). Pre-service teachers teaching about mathematics and their learning styles. Eurasia Journal of Mathematics, Sciene, \& Technology Education, 5(4), 335345.

Putwain, D. (2007). Researching academic stress and anxiety in students: Some methodological considerations. British Educational Research Journal, 33(2), 207219. https://doi.org/10.1080/01411920701208258

Ramirez, G., Chang, H., Maloney, E. A., Levine, S. C., \& Beilock, S. L. (2016). Journal of Experimental Child On the relationship between math anxiety and math achievement in early elementary school: The role of problem solving strategies. Journal of Experimental Child Psychology, 141, 83-100. https://doi.org/10.1016/j.jecp.2015.07.014

Rector, N. A., Bordeau, D., Kitchen, K., \& Massiah, L. J. (2005). Anxiety Disorders an Information Guide (1st ed.). Kanada: Centre for Addiction and Mental Health.

Ridder, H. G., Miles, M. B., Michael Huberman, A., \& Saldaña, J. (2014). Qualitative data analysis. A methods sourcebook. Zeitschrift Fur Personalforschung.

Rix, J. (2015). How Anxiety Scrambles Your Brain and Makes It Hard to Learn. Retrieved March 16, 2019, from https://www.theguardian.com/education/2015/nov/21/how-anxietyscrambles-your-brain-and-makes-it-hard-to-learn

Saglam, Y., Türker, B., \& Umay, A. (2011). Geometry anxiety scale for secondary school students. Procedia Social and Behavioral Sciences, 15(2011), 966-970. https:// doi.org/10.1016/j.sbspro.2011.03.222

Stuart, G. W. (2006). Buku Saku Keperawatan Jiwa. [Soul nursing pocket book]. Jakarta: EGC.

Van de Walle, J. A., Folk, S., Karp, K. S., \& Bay-Williams, J. M. (2013). Elementary and Midle School Mathematics: Theaching Developmentally. 8th ed. Boston: Pearson.

Walle, V. D. (1994). Elementary School Mathematics. New York: Longman.

Wu, S. S., Willcutt, E. G., Escovar, E., \& Menon, V. (2014). Mathematics Achievement and Anxiety and Their Relation to Internalizing and Externalizing Behaviors. Journal of Learning Disabilities, 47(6), 503-514.

https://doi.org/10.1177/0022219412473154 
Yudianto, E., \& Sunardi. (2015). Antisipasi siswa level analisis dalam menyelesaikan masalah geometri. [Anticipate student level analysis in solving geometry problems]. AdMathEdu, 5(2), 203-216.

Yudianto, E., Sunardi, Sugiarti, T., Susanto, Suharto, \& Trapsilasiwi, D. (2018). The identification of van Hiele level students on the topic of space analytic geometry. Journal of Physics: Conference Series, 983(1), 1-5. https:/ / doi.org/10.1088/17426596/983/1/012078 